\title{
Conocimientos y actitudes hacia la biotecnología en alumnos de último curso de Educación Secundaria Obligatoria
}

\author{
Marta de la Vega Naranjo ${ }^{1, a}$, Antonio Alejandro Lorca Marín ${ }^{1, b}$, María de los Ángeles \\ de las Heras Pérez ${ }^{1, c}$ \\ ${ }^{1}$ Departamento de Didácticas Integradas, Facultad de Educación, Psicología y Ciencias del Deporte, \\ Universidad de Huelva, Huelva, España. \\ -amarta.delavega@ddcc.ubu.es,'„antonio.lorca@ddcc.ubu.es,'angeles.delasheras@ddcc.ubu.es
}

[Recibido: 16 Octubre 2017. Revisado: 18 Febrero 2018. Aceptado: 23 Abril 2018]

\begin{abstract}
Resumen: Hoy día, muchos de los acontecimientos relacionados con la vida cotidiana tienen que ver directa o indirectamente con procesos biotecnológicos. Debido a ello y, dado que la biotecnología es una materia incluida en el currículo de la enseñanza secundaria obligatoria (ESO), se pretende conocer el nivel de conocimientos y la actitud hacia esta disciplina con la que termina el alumnado de esta etapa educativa. Para ello se realizó un estudio con 104 alumnos de $4^{\circ}$ curso de ESO en la Comunidad Autónoma de Andalucía. El estudio se realizó concretamente en varios centros de las provincias de Huelva y Málaga, a través de un cuestionario. El posterior análisis de los resultados nos sugiere que la mayoría de los alumnos que terminan la enseñanza obligatoria no poseen los conocimientos necesarios o mínimos para interpretar mucha de la información que se pone en juego en la sociedad actual. Además, se ha podido ver cómo sus actitudes hacia los diferentes procesos biotecnológicos están relacionadas con su nivel de conocimiento y con sus propias preconcepciones.
\end{abstract}

Palabras clave: Educación Secundaria Obligatoria; Biotecnología; Didáctica.

Knowledge and attitude towards biotechnology in students of the last course of Compulsory Secondary Education

\begin{abstract}
Today, many of the events related to everyday life have to do directly or indirectly with biotechnological processes. Due to this, and given that biotechnology is a subject included in the compulsory secondary education (ESO) curriculum, the aim is to know the level of knowledge and the attitude toward this discipline with which the students of this educational stage finishes. For this, a study was carried out with 104 students of the 4th year of ESO in the Autonomous Community of Andalusia. The study was carried out in two high schools in the provinces of Huelva and Malaga, through a questionnaire. The subsequent analysis of the results suggests that the majority of students who finish compulsory education do not have the necessary or minimum knowledge to interpret much of the information that is put into play in today's society. In addition, it has been possible to see how their attitude towards the different biotechnological processes is related to their level of knowledge and with their own conceptions.
\end{abstract}

Keywords: Compulsory Secondary Education; Biotechnology; Didactic.

Para citar este artículo: De la Vega-Naranjo M., Lorca-Marín A.A., De las Heras-Pérez M.A. (2018) Conocimientos y actitudes hacia la biotecnología en alumnos de último curso de Educación Secundaria Obligatoria. Revista Eureka sobre Enseñanza y Divulgación de las Ciencias 15(3), 3301. doi: 10.25267/Rev_Eureka_ensen_divulg_cienc.2018.v15.i3.3301

\section{Introducción}

A lo largo de los últimos años, muchos estudios han hecho hincapié en la presencia de déficit conceptual y actitudinal de los estudiantes de diferentes edades hacia los procesos afines con la biotecnología y sus conceptos relacionados. Como indicó Pedrancini (2007), existe un desconocimiento más o menos general sobre el significado de organismo transgénico. Además, los estudiantes no conocen las diferencias entre los cultivos convencionales de plantas y los genéticamente modificados (Ekborg 2008). Del mismo modo, existe una gran falta de conocimiento sobre los principios básicos de ingeniería genética (Lewis y Wood-Robinson

\author{
Revista Eureka sobre Enseñanza y Divulgación de las Ciencias \\ Universidad de Cádiz. APAC-Eureka. ISSN: 1697-011X \\ bttp:/ / dx.doi.org/10.25267/Rev_Eureka_ensen_divulg_cienc.2018.v15.i3.3301 \\ bttp:/ / reuredc.uca.es
}


2000). Sin embargo, aunque existe un gran porcentaje de estudiantes que sí conocen esta terminología, no comprenden lo que conllevan (Aznar 2000, Pedrancini 2007).

La sociedad actual se caracteriza por estar muy influenciada por la Ciencia (Russell, Huelin y Sacristán, 1982). Nuestra vida cotidiana está llena de actividades y hechos que nos exigen estar informados o tener ciertos conocimientos sobre conceptos científicos. Muchos de estos conceptos básicos, necesarios para interpretar algunos de estos fenómenos de la vida cotidiana, proceden de las ciencias naturales, concretamente de la Biología y la Geología. El objetivo de las disciplinas relacionadas con la biología es comprender la naturaleza y el significado del amplio campo de fenómenos que se presentan en nuestras vidas. Esto es lo que se denomina alfabetización científica, el cual quedó definido por Bybee (1997).

De las materias relacionadas con las ciencias naturales, debe destacarse su carácter empírico y mayoritariamente experimental. El desarrollo de estas materias debe mostrar los usos aplicados de las ciencias, sus implicaciones sociales y tecnológicas y valorar las implicaciones éticas de la investigación científica. De este modo, deben de producir el acercamiento a las causas y desarrollo de los grandes problemas que se presentan en la sociedad actual, como son la desigualdad en la distribución de la riqueza, las cuestiones derivadas de los problemas medioambientales y el desarrollo tecnológico, la investigación genética, el papel de los medios de comunicación y su repercusión en el consumo y en los estilos de vida, las drogodependencias, etc. Esto permitirá potenciar una serie de valores como la solidaridad, la oposición a cualquier tipo de discriminación por razón de sexo, raza o creencia, la resolución pacífica de los conflictos, etc., que facilite a los alumnos su integración en una sociedad democrática, responsable y tolerante. Existe un gran abanico de investigaciones en el campo de la enseñanza de la Ciencia que han mostrado que tanto estudiantes como profesores no alcanzan una comprensión adecuada de las cuestiones que se abordan en la educación científico-tecnológica (Solbes y Vilches 2002, Acevedo 2003, Dawson y Schibeci 2003, Solbes y Vilches 2004).

Como describe Sadler (2004), siempre ha estado claro que los estudiantes de ciencias deben aprender conceptos científicos, pero no ha sido tan obvio para qué necesitan usar esa información o cómo transfieren el conocimiento científico a la vida cotidiana. Esto ocurre, especialmente, en la toma de decisiones en temas socio-científicos, al tiempo que se reconoce que la aplicación del conocimiento aprendido en nuevas situaciones y contextos es poco frecuente en las clases de ciencias.

Pero al igual que vemos la importancia de que los alumnos adquieran un buen grado de alfabetización científica, también hay que tener en cuenta cómo la sociedad va guiando las necesidades de los planes de estudios hacia nuevos horizontes. "En los últimos años, ha surgido un fenómeno, conocido como tecnologías del aprendizaje y el conocimiento (TACs), que ha supuesto una nueva concepción del uso y la forma de pensar en la web y que un profesional de la educación no puede dejar de plantearse y preguntarse sobre su uso en el aula" (Lorca-Marín, 2016). "En relación a esta realidad social, en la que se mueve el alumnado, nos interesa utilizar tales destrezas y habilidades para desarrollar otros hábitos relacionados con la docencia: comunicación, diversión, motivación..." (Lorca-Marín et al, 2014) Sin embargo, este cambio tan plausible no se aprecia de la misma forma cuando hablamos de otros adelantos en la sociedad como es, por ejemplo, la Biotecnología, que se encuentra tan en auge en la actualidad. 


\section{Marco Teórico}

Teniendo en cuenta la importancia que tiene la alfabetización científica en el mundo actual y, en concreto, haciendo hincapié en la Biotecnología como fuente de muchos avances y controversias en la actualidad, nos proponemos en este trabajo conocer qué conocimientos acerca de la Biotecnología poseen los alumnos que terminan la ESO, así como sus actitudes hacia ella.

El planteamiento de esta investigación surge para dar respuesta a la siguiente cuestión:

¿Qué conocimientos sobre Biotecnología tienen los alumnos que acaban la enseñanza secundaria obligatoria y qué actitudes poseen hacia los procesos biotecnológicos?

Este problema principal hace que se planteen los siguientes objetivos para este estudio:

I. Analizar el grado de conocimiento de los alumnos hacia la diferenciación entre productos y procesos biotecnológicos producidos de forma tradicional o moderna. Estudiar si existen diferencias entre las dos provincias estudiadas y el sexo de los alumnos en cuanto a los conceptos planteados.

II. Analizar si existen claras evidencias de concepciones erróneas heredadas de la sociedad en los alumnos, después de terminar los estudios de Secundaria Obligatoria.

III. Conocer la actitud de los alumnos hacia diferentes procesos biotecnológicos.

De esta manera pretendemos abordar las posibles deficiencias que se puedan generar en el proceso de enseñanza-aprendizaje de la biotecnología en secundaria.

En su trabajo, Ocelli, Vilar, Valeira (2011) en Argentina, describen cómo la mayoría de los estudiantes sólo vinculan a la Biotecnología las actividades que implican directamente a la ingeniería genética, dejando de lado otras cuestiones relacionadas con lo que hemos descrito como Biotecnología Tradicional.

Gunter, Kinderlerer y Beyleveld (1998) examinaron los conocimientos y la opinión de 48 adolescentes hacia la Biotecnología, con especial referencia a la producción de alimentos. Los resultados mostraron que, a pesar de los bajos conocimientos de estos jóvenes sobre las ciencias biológicas, parecían menos reticentes hacia el uso de alimentos procedentes de organismos genéticamente modificados que un grupo de adultos encuestados. En general, los adolescentes consideran la ingeniería genética de plantas como más aceptable que en el caso de los animales. Sus razones para oponerse a la ingeniería genética de los animales era que se trataba de «no natural», «peligroso», «no se debe hacer» y «poco ética»; razones similares fueron encontradas por Hill, Stannistreet, O'Sullivan y Boyes (1999), que examinaron las actitudes de 778 estudiantes de edades comprendidas entre 11 y 18 años sobre el uso de animales modificados genéticamente en la investigación médica. En su estudio, el $42 \%$ de la muestra consideró que no se debe permitir, porque era cruel (47\%) o no naturales (53\%).

Además, varios autores concluyen que las percepciones de la seguridad de la biotecnología se correlacionan con la utilidad que esta tenga (Gaskell 2000, Powell 2000). Tegegne y colaboradores (2013) describen como las percepciones de la población acerca de la biotecnología también están relacionadas con su nivel de conocimiento. Postulan que los individuos mejor informados tenían opiniones más favorables acerca de la biotecnología. Otro factor importante en las percepciones sobre biotecnología viene dado por la legislación vigente en cada país. Países donde el uso de alimentos transgénicos u otro tipo de procesos biotecnológico estén prohibido por ley, tendrán una disposición más contraria al uso de estas técnicas que en países donde su uso esté permitido y bien extendido (Prokop, Lesková, Kibiatko y Diran 2007). 
Prokop (2007) en su estudio con alumnos de distintos niveles en Eslovaquia, concluyó que las mujeres aceptaban peor los productos basados en ingeniería genética que los hombres. Datos similares fueron detectados por varios autores (Luján y Todt 2000, Blaine, Kamaldeen y Powell 2002, von Roten 2004, Crne-Hladnik, Peklaj, Kosmelj, Hladnik y Javornik 2009, Özel, Erdogan, Usak y Prokop 2009). Simons (2010) postula que el nivel de conocimiento tiene una relación directa con la actitud hacia la biotecnología en hombres, e inversa con las mujeres.

\section{Metodología}

El estudio que se plantea se ha llevado a cabo con alumnos de último curso de ESO que cursaban la asignatura de Biología y Geología. El número total del alumnado estudiado ha sido 104, de los cuales 50 fueron de centros de la provincia de Málaga y 54 de centros de la provincia de Huelva. Del total del alumnado, 38 fueron chicos y 66 chicas (Edad Media: 16,24 años; SD: 0,83).

Para la recogida de datos se conformó un cuestionario a partir de los utilizados por distintos autores (Cavanagh, Hood y Wilkinson 2004, Tegegne, Aziz, Bhavsar y Wiemers 2013) y que nos permite cumplir los criterios de validez y fiabilidad propios de este tipo de instrumento. El cuestionario utilizado (Anexo I) presenta tres partes:

Parte 1: se plantearon una serie de ítems de respuesta cerrada, para saber el conocimiento de los alumnos sobre productos elaborados o no, mediante Biotecnología. Para ello, se presentan un conjunto de ítems que correspondían a productos y procesos producidos o que se pueden producir mediante biotecnología, diferenciándose entre un primer grupo que engloba a los cinco primeros productos y que tienen que ver con la Biotecnología Tradicional (cerveza, queso, vino, yogurt y pan) y un segundo grupo, que engloba al resto de los productos y procesos y que son considerados como Biotecnología Moderna. Además, se pueden diferenciar también dos subgrupos dentro de los ítems de la Biotecnología Moderna, un grupo relacionado con biomedicina (clonación, inseminación artificial, medicinas y vacunas) y otro relacionado con términos sobre el medio ambiente y la alimentación (combustibles, limpieza de aguas residuales, plantas resistentes a plagas de insectos y frutos ricos en diferentes compuestos).

Parte 2: se planteó a los alumnos una serie de afirmaciones sobre procesos biotecnológicos, con las que pudiéramos evidenciar la existencia de concepciones previas en el alumnado. En este caso, el alumnado debía responder a las cuestiones mediante VERDADERO, FALSO o NS/NC (no sabe/no contesta).

Parte 3: por último, se utilizaron una serie de ítems de respuesta cerrada para conocer la opinión de los alumnos hacia diferentes procesos biotecnológicos, para ver si estaban A FAVOR o EN CONTRA de cada uno de ellos. Además, a los alumnos se les dejó un espacio para que dieran sus opiniones si lo veían necesario. En esta parte se podía diferenciar, a su vez, grupos de ítems que englobarían el uso en biotecnología de microorganismos (ítems a y b), para evitar o tratar enfermedades (items g y h), de plantas y animales (items c, d, e, f, i, j y k) o para la clonación y elección de rasgos físicos en los futuros hijos (ítems 1 y m).

Los datos obtenidos se trataron mediante paquete estadístico SPSS realizándose un análisis de frecuencias. Para estudiar la existencia de diferencias significativas en las respuestas dadas por los alumnos a las preguntas formuladas entre provincias y entre ambos sexos, se llevó a cabo un análisis Chi-cuadrado, estableciendo un nivel de significación de $p=0,05$. 


\section{Resultados y Discusión}

Se presentan y discuten a continuación, los resultados obtenidos según las tres partes en las que se divide el instrumento de recogida de datos.

\section{PARTE 1}

Los resultados obtenidos se han representado mediante diagrama de barras, representando el porcentaje de alumnos que han respondido correctamente a cada uno de los ítems propuestos (figura 1).

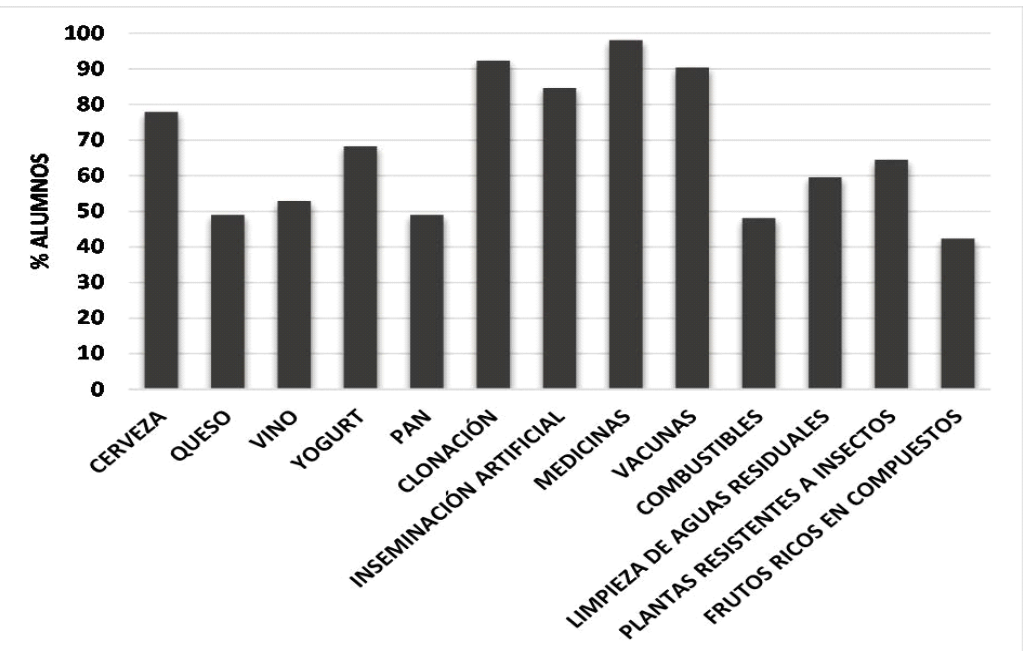

Figura 1. Porcentaje del alumnado que ha respondido correctamente a cada uno de los ítems propuestos para evidenciar los conocimientos que poseen sobre procesos y productos realizados mediante biotecnología tradicional y moderna.

Como se puede observar, los productos o procesos del grupo relacionado con la biomedicina son los que obtienen un mayor porcentaje de acierto, rondando el $90 \%$. Sin embargo, los ítems del grupo de Biotecnología Tradicional y los relacionados con procesos medioambientales o de alimentación obtienen porcentajes de acierto mucho menores, de alrededor del 50\%. Los resultados obtenidos son muy similares a los obtenidos por Occelli (2011). Esto puede deberse a que los procesos biotecnológicos que con más frecuencia aparecen en los medios de comunicación, son los relacionados con la ingeniería genética.

Para estudiar la incidencia de estos datos en relación a las dos provincias andaluzas estudiadas hemos realizado una representación de los porcentajes de acierto obtenidos por provincia. Estos resultados se muestran en la figura 2. 


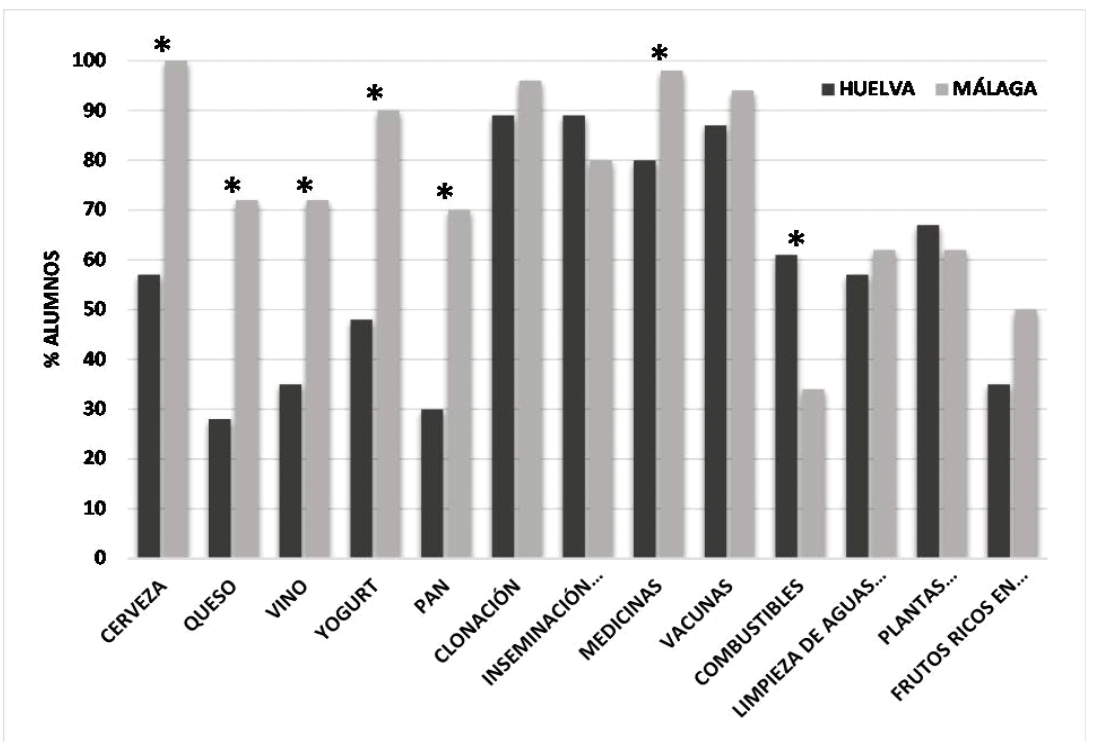

Figura 2. Porcentaje del alumnado que ha respondido correctamente a cada uno de los ítems propuestos en la Parte 1 en relación a cada provincia andaluza estudiada. Con un asterisco se señalan las parejas de porcentajes de respuestas que presentan diferencias estadísticamente significativas.

En este gráfico observamos cómo existe una clara distinción entre provincias en referencia a los ítems relacionados con los productos de Biotecnología Tradicional, mostrando una deficiencia en el proceso de aprendizaje en la provincia de Huelva. Podemos observar cómo estos ítems pasan de tener un porcentaje de acierto de alrededor del $40 \%$ en Huelva a un porcentaje de acierto que ronda el $80 \%$ en Málaga. Las diferencias encontradas son estadísticamente significativas y por tanto podemos inferir que existen diferencias observables entre las respuestas de las dos provincias con relación a estos cinco primeros ítems. El resto de los ítems se mantienen de forma similar en ambas provincias.

Por otro lado, y con el objetivo de redondear los resultados obtenidos para esta primera cuestión, hemos representado los porcentajes de acierto estudiados según el sexo del alumnado, para ver si existen diferencias en el aprendizaje con relación a este parámetro. Varios estudios sugieren que existe una clara diferencia en el proceso de aprendizaje entre chicos y chicas (Vázquez, Acevedo, Manassero y Acevedo 2006; Usak, Erdogan, Prokop y Ozel 2009). Sin embargo, como se observa en la figura 3, en nuestro trabajo no hemos encontrado diferencias observables en las respuestas según el sexo de ninguno de los ítems estudiados. 


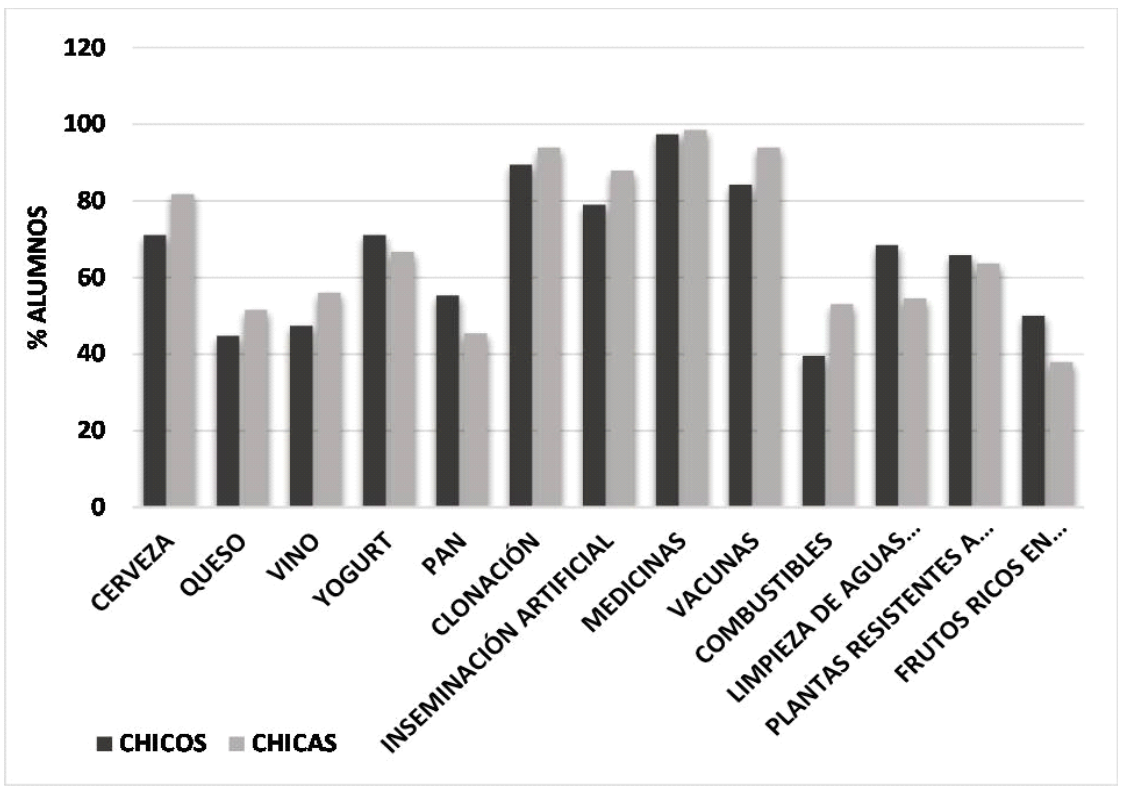

Figura 3. Porcentaje del alumnado que ha respondido correctamente a cada uno de los ítems propuestos en la Parte 1 en relación al sexo.

\section{PARTE 2}

Para evidenciar la existencia de preconcepciones en el alumnado, se llevó a cabo la segunda parte del cuestionario. Los resultados cuantificados de esta cuestión se muestran en la Tabla 1. De los datos analizados se pueden sacar varias conclusiones importantes. Lo primero que se observa cuando miramos la tabla es que hay alrededor de un $20 \%$ de la población estudiada (Media: 20,8125; SD: 9,02011641) que contesta NS/NC a las cuestiones planteadas. Resulta un valor muy elevado, teniendo en cuenta el nivel de estudios y la dificultad de las afirmaciones planteadas.

$\mathrm{Si}$ analizamos uno por uno los ítems planteados podemos sacar algunos puntos calientes. Algunos de los ejemplos más importantes son.

$1^{\circ}$. El 18\% de los encuestados cree que los tomates naturales no contienen ADN. Si a este resultado le sumamos el $12 \%$ de alumnos que contestan NS/NC, tenemos un total de un $30 \%$ que responden de forma incorrecta a la afirmación «Los tomates normales no contienen genes mientras que los genéticamente modificados sí»».

$2^{\circ}$. El siguiente ítem afirma que «La clonación de seres humanos da una descendencia totalmente idéntica, incluyendo rasgos físicos y de personalidad», a la que un $32 \%$ de los alumnos ha respondido que es verdadero. Este dato sumado al $11 \%$ que responde NS/NC hace un total de un $43 \%$ de respuestas no correctas.

$3^{\circ}$. Un $25 \%$ de los alumnos no responden correctamente a la afirmación «La levadura utilizada para fabricar pan contiene organismos vivos».

$4^{\circ}$. Un total de un 53\% no responde correctamente a la afirmación «Cuando comes carne estás comiendo también ADN o genes».

$5^{\circ}$. En la afirmación «La producción tradicional del vino o la cerveza no se consideran biotecnología», un $32 \%$ de los alumnos responde que es verdadero.

$6^{\circ}$. Un total de $61 \%$ de los alumnos contesta de forma no correcta a la afirmación «Con biotecnología se puede producir combustible a partir de aceites». 
Tabla 1. Porcentaje de alumnos que han respondido VERDADERO, FALSO o NS/NC a las diferentes afirmaciones propuestas en la Parte 2.

\begin{tabular}{|c|c|c|c|}
\hline & \multicolumn{3}{|c|}{$\%$ ALUMNOS } \\
\hline & VERDADERO & FALSO & $\mathrm{NS} / \mathrm{NC}$ \\
\hline $\begin{array}{l}\text { a) Los tomates normales no contienen genes mientras que } \\
\text { los genéticamente modificados si }\end{array}$ & 18 & 70 & 12 \\
\hline $\begin{array}{l}\text { b) La clonación de seres humanos da una descendencia } \\
\text { totalmente idéntica, incluyendo rasgos físicos y de } \\
\text { personalidad }\end{array}$ & 32 & 58 & 11 \\
\hline $\begin{array}{l}\text { c) Si una persona como fruta genéticamente modificada, sus } \\
\text { propios genes pueden resultar modificados }\end{array}$ & 7 & 82 & 12 \\
\hline $\begin{array}{l}\text { d) La levadura utilizada para fabricar pan contiene } \\
\text { organismos vivos }\end{array}$ & 75 & 11 & 14 \\
\hline e) Es imposible transferir genes de animales a plantas & 33 & 36 & 32 \\
\hline $\begin{array}{l}\text { f) La biotecnología permitirá el tratamiento y/o la cura de } \\
\text { enfermedades genéticas humanas }\end{array}$ & 82 & 5 & 13 \\
\hline $\begin{array}{l}\text { g) La biotecnología solo se relaciona con plantas } \\
\text { genéticamente modificadas como el arroz }\end{array}$ & 3 & 75 & 22 \\
\hline $\begin{array}{l}\text { h) La introducción de plantas y animales genéticamente } \\
\text { modificados en alimentos de consumo humano tendrá } \\
\text { efectos negativos sobre la salud humana }\end{array}$ & 30 & 33 & 38 \\
\hline $\begin{array}{l}\text { i) La biotecnología tendrá un gran impacto en la prevención, } \\
\text { diagnóstico y tratamiento del cáncer }\end{array}$ & 66 & 9 & 25 \\
\hline $\begin{array}{l}\text { j) Cuando comes carne estás comiendo también ADN o } \\
\text { genes }\end{array}$ & 47 & 25 & 28 \\
\hline $\begin{array}{l}\text { k) Actualmente existen medicinas que están producidas por } \\
\text { biotecnología o ingeniería genética }\end{array}$ & 80 & 3 & 17 \\
\hline $\begin{array}{l}\text { 1) La biotecnología produce nuevas variedades de plantas } \\
\text { resistentes a ciertas plagas de insecto para evitar el uso de } \\
\text { pesticidas }\end{array}$ & 68 & 13 & 19 \\
\hline $\begin{array}{l}\text { m) La biotecnología puede mejorar el contenido nutricional } \\
\text { de alimentos y su coste de producción }\end{array}$ & 56 & 21 & 23 \\
\hline $\begin{array}{l}\text { n) Existen microorganismos capaces de descomponer y } \\
\text { depurar las aguas residuales }\end{array}$ & 72 & 18 & 10 \\
\hline $\begin{array}{l}\text { ñ) La producción tradicional del vino o la cerveza no se } \\
\text { consideran biotecnología }\end{array}$ & 32 & 47 & 21 \\
\hline $\begin{array}{l}\text { o) Con biotecnología se puede producir combustibles a } \\
\text { partir de aceites }\end{array}$ & 39 & 25 & 36 \\
\hline
\end{tabular}

Los resultados obtenidos en los ítems denominados a), b), c), d) y e) se han comparado con los resultados obtenidos por Cavanagh (2004), en cuyo estudio realizó estas mismas preguntas en alumnos de secundaria con una media de 16,1 años de edad de una población rural de Australia. Esto puede denotar que las deficiencias encontradas no sean particularidades, sino errores generalizados en la población de estudiantes de estas edades. Otros ítems estudiados por esta autora tienen un porcentaje de acuerdo similar al encontrado en nuestro estudio, como son los ítems denominados f), h) e i).

Otro estudio realizado a alumnos universitarios del Estado de Tenessee en Estados Unidos planteó un par de ítems similares a los nuestros. Los ítems de los que hablamos son los que hemos nombrado como j) y k). Los resultados fueron, al igual que pasó anteriormente, muy similares a los obtenidos en nuestro estudio (Tegegne 2013). Esto puede demostrar que las preconcepciones adquiridas durante la infancia son verdaderamente difíciles de cambiar durante el periodo de aprendizaje que contempla tanto la enseñanza secundaria obligatoria como la post-obligatoria. Resultados similares se obtuvieron en un estudio realizado en Turquía por Usak (2009). 
Como hemos visto, el problema en la carencia de conocimientos en el área de la biotecnología puede deberse a las propias concepciones previas que poseemos por herencia de la sociedad. McHughen (2007), realizó una revisión acerca de este tema. En ella habla, entre otras cosas, de las concepciones previas del público en general sobre cuestiones de biotecnología y cómo éstas pueden llevarnos a entorpecer nuestra relación con la sociedad en la toma de decisiones o elecciones.

\section{PARTE 3}

Respecto a las actitudes de los alumnos hacia los procesos biotecnológicos, se propuso una última tarea. Los resultados que se obtuvieron del recuento de respuestas tomadas de los 104 alumnos en esta tercera parte se muestran en la Tabla 2. Como podemos observar existe un alto nivel de opiniones a favor del uso de microorganismos en Biotecnología, al igual que ocurre con el grupo formado por los ítems g) y h), que tratan de su uso para evitar o tratar enfermedades. Sin embargo, los ítems que hablan del uso de plantas y animales, se encuentran valorados a razón de $50 \%$ a favor $50 \%$ en contra. El único de estos ítems mal valorado es el que corresponde con la introducción de genes de plantas en animales.

Tabla 2. Porcentaje de alumnos que han respondido A FAVOR o EN CONTRA en los diferentes ítems propuestos en la Parte 3.

\begin{tabular}{|c|c|c|}
\hline & \multicolumn{2}{|c|}{$\%$ ALUMNOS } \\
\hline & A FAVOR & EN CONTRA \\
\hline a) Uso de levaduras para producción de vino y cerveza & 77 & 16 \\
\hline $\begin{array}{l}\text { b) Uso de microorganismos genéticamente modificados para } \\
\text { depuración de aguas residuales de forma más eficiente }\end{array}$ & 77 & 9 \\
\hline c) Alteración de genes de plantas para un mejor crecimiento & 50 & 45 \\
\hline d) Añadir genes a plantas para que tengan un mayor valor nutricional & 59 & 38 \\
\hline e) Alteración de genes en frutos para que tengan un mejor sabor & 54 & 42 \\
\hline f) Alteración de genes en frutos para duren más tiempo en buen estado & 57 & 38 \\
\hline $\begin{array}{l}\text { g) Alteración de genes de humanos para el tratamiento de } \\
\text { enfermedades }\end{array}$ & 88 & 7 \\
\hline h) Alteración de genes en embriones para evitar enfermedades & 82 & 15 \\
\hline $\begin{array}{l}\text { i) Usar vacas genéticamente modificadas para mejorar la calidad de la } \\
\text { carne y la leche }\end{array}$ & 53 & 42 \\
\hline $\begin{array}{l}\text { j) Usar vacas genéticamente modificadas para producir medicinas de } \\
\text { uso humano }\end{array}$ & 51 & 42 \\
\hline k) Insertar genes de plantas en animales & 20 & 69 \\
\hline 1) Clonación de seres humanos & 18 & 76 \\
\hline m) Elección del color de los ojos de los futuros hijos & 30 & 64 \\
\hline
\end{tabular}

Mohapatra y colaboradores (2010) describieron que el público, en general, posee una buena actitud hacia los organismos genéticamente modificados, pero depende del organismo en cuestión. Así, el uso de microorganismos y plantas para modificación genética está mucho mejor visto que el uso de animales y personas, a no ser que este uso sea para la producción de medicinas o para el estudio de enfermedades humanas. Datos similares han sido presentados por Usak y colaboradores (2009), analizaron la actitud hacia la biotecnología de alumnos de Turquía y encontraron que había una amplia aprobación de la biotecnología y la ingeniería genética aplicada a plantas y microorganismos, pero no a los animales.

Finalmente, nos encontramos con un grupo formado por los ítems 1 ) y m), referentes a la clonación y a la elección de rasgos físicos en los futuros hijos. En este caso solo entre un 20 $25 \%$ de los alumnos se postulan a favor de su uso en biotecnología.

En esta tercera parte del cuestionario se incluyó un apartado en blanco para que los alumnos escribieran alguna observación que creyeran oportuna en cada uno de los ítems. Muchos de estos comentarios eran a favor del uso de la biotecnología y versaban sobre que «Todo avance 
científico es beneficioso» o «Todo es bueno mientras no traspase las barreras éticas»y «Mientras no cause problemas para la salud».

Por otro lado, también hubo razones con respecto a situaciones en contra, algunas de las cuales decían que «No es natural», «No es ético», «Se corren riesgos no necesarios», «Es peligroso» o incluso que «No creo que eso sea posible». Estas afirmaciones resultan similares a las encontradas por Gunter y colaboradores (1998).

Al igual que hicimos en la Parte 1, hemos querido ver si existen diferencias observables entre las respuestas de opinión dadas por chicos y chicas. Tras realizar el análisis a las parejas de respuestas (datos no mostrados), se ha observado que no existen diferencias observables en ninguno de los ítems estudiados. Con estos resultados no podemos concluir que exista algún tipo de distinción por género a la hora de valorar los procesos biotecnológicos. Al contrario que los resultados obtenidos por otros autores (Prokop 2007, Luján y Todt 2000, Blaine 2002, von Roten 2004, Crne-Hlandnik 2009, Özel 2009).

\section{Conclusiones}

Los estudiantes presentan bastantes carencias en conceptos básicos, así no vinculan los procesos de Biotecnología Tradicional con el término Biotecnología. Esto indica que pueden no conocer los procedimientos a través de los cuales se producen alimentos como el pan o el queso, y posiblemente ignoran que los microorganismos participan en este proceso. Sin embargo, los alumnos poseen un buen conocimiento de conceptos más relacionados con la Biotecnología Moderna. Habría que plantearse producir materiales docentes que permitan una mejor comprensión de estos conceptos. Por ello, pensamos que sería muy importante a la hora de planificar propuestas didácticas referidas a contenidos biológicos, que se les vinculara con los procesos biotecnológicos, utilizando esta área como un contenido transversal durante toda la etapa de educación secundaria.

Además de la falta de conocimientos en una gran parte de los conceptos relacionados con la biotecnología, se han podido captar muchas preconcepciones de los alumnos, ya no solo directamente relacionados con la biotecnología, sino también con la biología en general. Muchas de estas concepciones se relacionan directamente con la falta de conocimiento de puntos clave de la genética como el propio conocimiento del ADN y su transmisión.

Las actitudes de los alumnos hacia los diferentes procesos biotecnológicos vienen directamente influenciadas por su propio conocimiento sobre el tema, pero también por sus propias concepciones procedentes de la sociedad y de los medios de comunicación. Así, se ha observado en los resultados de este estudio como los alumnos aumentan su desacuerdo con el uso de la biotecnología a medida que hay un aumento de complejidad de los organismos utilizados en dichos procesos. De este modo, se sienten muy de acuerdo en el uso de microorganismos, pero este disminuye cuando hablamos de plantas y animales, y cae cuando nos referimos a seres humanos. Sólo cuando el uso de la biotecnología en seres humanos es referido a mejoras en la salud, los alumnos prestan algo más de acuerdo.

Aunque se han observado ciertas diferencias entre las provincias estudiadas, no debemos inferir que existan las mismas a la hora de estudiar los resultados por razón de sexo. En cualquiera de los casos, debemos profundizar en posteriores investigaciones las razones por las que ocurren estos hechos.

En general, los estudiantes tienen escaso conocimiento en ciertas áreas de la biotecnología y numerosas concepciones erróneas acerca de lo que significa la biotecnología, lo que sugiere 
que el currículo de ciencias con respecto a este tema debe ser en gran medida revisado y se deben mejorar las estrategias de enseñanza.

\section{Referencias}

Acevedo JA, Vázquez A, Manassero MA. (2003) Evaluación de actitudes y creencias CTS: diferencias entre alumnos y profesores. Revista de Educación 328: 355-382.

Aznar V. (2000) ¿Qué sabemos sobre biotecnología? Alambique 25: 9-14.

Blaine K, Kamaldeen S, Powell D. (2002) Public perceptions of biotechnology. Journal of Food Science 67(9):3200-3208.

Bybee R. (1997) Towards an understanding of Scientific Literacy. En: Graeber W and Bolte C (Eds). Scientific Literacy. Kiel. IPN.

Cavanagh H, Hood J, Wilkinson J. (2004) Riverina High School student's views of biotechnology. Issues in Biotechnology Teaching 8(2):121-127.

Crne-Hladnik H, Peklaj C, Kosmelj K, Hladnik A, Javornik B. (2009) Assessment of Slovene secondary school students' attitudes to biotechnology in terms of usefulness, moral acceptability and risk perception. Public Understanding of Science 18:747-758.

Dawson V, Schibeci R. (2003) Western Australian high school students' attitudes towards biotechnology processes. Journal of Biological Education 38(1): 7-12.

Ekborg M. (2008) Opinion building on a socio-scientific issue: the case of genetically modified plants. Journal of Biological Education 42(2):60-65.

Gaskell G. (2000) Agricultural biotechnology and public attitudes in European Union. AgBioForum 3(2-3):87-96.

Gunter B, Kinderlerer J, Beyleveld D. (1998) Teenagers and biotechnology: A survey of understanding and opinion in Britain. Studies in Science Education 8(32):81-112.

Hammer O, Harper DAT, Ryan PD. (2001) PAST: Palaeontological statistics software package for education and data analysis. Palaeontologia Electronica 4(1): 9

Hill R, Stannistreet M, O’Sullivan H, Boyes E. (1999) Genetic engineering of animals for medical research: students' views. School Science Review 80:23-30.

Lewis J, Wood-Robinson C. (2000) Genes, chromosomes, cell divition and inheritance - do students see any relationship? International Journal of Science Education 22(2):177-195.

Lorca-Marín, A.A., Vázquez-Bernal, B. y Rosa, S. (2014) "Los videojuegos para el profesorado en formación inicial de educación Infantil en la enseñanza de las Ciencias de la Naturaleza" en De las Heras, M.A., Lorca-Marín, A.A, Vázquez-Bernal, B., Wamba,A. y Jiménez, R. (Eds).(2014) Investigación y transferencia para una educación en ciencias: un reto emocionante. XXVI Encuentro de Didáctica de las Ciencias Huelva: Universidad de Huelva. pp:781-788.

Lorca-Marín, A.A., Cuenca, J. M., Vázquez-Bernal, B. y Lorca, J. A. (2016). ¿Qué concepciones tienen los docentes en ejercicio y en formación inicial, sobre el uso didáctico de los videojuegos? En J. L. Bravo Galán (Ed.) 27 Encuentros de Didáctica de las Ciencias Experimentales. Badajoz: UEX-APICE. pp:543-551

Luján JL, Todl O. (2000) Perceptions, attitudes and ethical valuations: the ambivalence of the public image of biotechnology in Spain. Public Understanding of Science 9:383-392. 
McHughen A. (2007) Public perceptions of biotechnology. Biotechnology Journal 2(9): 11051111.

Mohapatra AK, Priyadarshini D, Biswas A. (2010) Genetically modified food: knowledge and attitude of teachers and students. Journal of Science Education Technology 19:489-497.

Ocelli M, Vilar TM, Valeiras N. (2011) Conocimientos y actitudes de estudiantes de la ciudad de Córdoba (Argentina) en relación a la biotecnología. Revista Electrónica de Enseñanza de las Ciencias 10(2):227-242.

Özel M, Erdogan M, Usak M, Prokop P. (2009) High school students' knowledge and attitudes regarding biotechnology applications. Educational Science 9(1):321-328.

Pedrancini V, Corazza-Nunes MJ, Galluch MT, Moreira AL, Nunes WM. (2007) Saber científico e conhecimiento espontâneo: opiniões de alunos do ensinomédio sobre transgénicos. Ciência e Educão 14(1): 135-146.

Powell DA. (2000) Food safety and the consumer-perils of por risk communication. Canadian Journal of Animal Science 80(3):393-404.

Prokop P, Lesková A, Kibiatko M, Diran C. (2007) Slovakian students' knowledge of and attitudes toward biotechnology. International Journal of Science Education 29(7):895-907.

Russell, B., Huelin, G. S., \& Sacristán, M. (1969). La perspectiva científica. Ariel.

Sadler TD. (2004) Informal reasoning socioscientific issues: a critical review of research. Journal of Research in Science Teaching 41(5):513-536.

Simons R. (2010) Gender differences in knowledge and attitude towards biotechnology. Public Understanding of Science 19(6):642-653.

Solbes J, Vilches A. (2004) Papel de las relaciones entre ciencia, tecnología, sociedad y ambiente en la formación ciudadana. Enseñanza de las Ciencias 22(3):337-348.

Solbes J, Vilches A. (2002) Visiones de los estudiantes de secundaria acerca de las interacciones Ciencia, Tecnología y Sociedad. Revista Electrónica de Enseñanza de las Ciencias 1(2).

Tegegne F, Aziz A, Bhavsar H, Wiemers R. (2013) Awarenesis of and attitudes towars biotechnology by Tenesse State university students with different backgrounds and majors. Journal of Biotechnology Research 5:16-23.

Usak M, Erdogan M, Prokop P, Ozel M. (2009) High school and University students' knowledge and attitudes regarding biotechnology. A Turkish experience. Biotechnology Education 37(2):123-30.

Vázquez A, Acevedo JA, Manassero MA, Acevedo P. (2006) Evaluación de los efectos de la materia CTS de bachillerato en las actitudes CTS del alumnado con metodología de respuesta múltiple. Revista Eureka de Enseñanza de Divulgación Científica 3(3):317-348.

von Roten FC. (2004) Gender differences in attitudes toward science in Switzerland. Public Undertanding of Science 13:191-199. 


\section{Anexo I: CUESTIONARIO SOBRE CONOCIMIENTOS Y ACTITUD HACIA LA BIOTECNOLOGÍA}

Se va a realizar un trabajo de investigación sobre qué conocimientos tiene el alumnado acerca de la Biotecnología y cuál es su actitud hacia ella. Para ello, este cuestionario cuenta con tres partes, las dos primeras sobre conceptos y la tercera sobre la opinión del alumnado hacia la Biotecnología.

Instituto:Género:Edad:Curso:

\begin{tabular}{|l|l|l|}
\hline $\begin{array}{l}\text { PARTE 1. De los siguientes procesos y productos, ¿cuáles pueden estar } \\
\text { realizado a partir de métodos biotecnológicos? Marque con una X) }\end{array}$ & SI & NO \\
\hline Cerveza & & \\
\hline Queso & & \\
\hline Vino & & \\
\hline Yogurt & & \\
\hline Pan & & \\
\hline Clonación & & \\
\hline Inseminación Artificial & & \\
\hline Medicinas & & \\
\hline Vacunas & & \\
\hline Combustibles & & \\
\hline Limpieza de Aguas Residuales & \\
\hline Plantas resistentes a insectos & \\
\hline Frutos ricos en diferentes compuestos & \\
\hline
\end{tabular}

PARTE 2. Las siguientes afirmaciones son: (Marque con una $\mathrm{X}$ )

Los tomates normales no contienen genes mientras que los genéticamente modificados si

La clonación de seres humanos da como resultado una descendencia perfectamente idéntica, incluyendo rasgos físicos y de personalidad

Si una persona come fruta genéticamente modificada, sus propios genes pueden resultar modificados

La levadura utilizada para fabricar pan contiene organismos vivos Es imposible transferir genes de animales a plantas

La biotecnología permitirá el tratamiento y/o la cura de enfermedades genéticas humanas

La biotecnología solo se relaciona con plantas genéticamente modificadas como el arroz

La introducción de plantas y animales genéticamente modificados en alimentos de consumo humano tendrá efectos negativos sobre la salud humana

La biotecnología tendrá un gran impacto en la prevención, diagnóstico y tratamiento de cáncer

Cuando comes carne estas tomando también ADN o genes

Actualmente existen medicinas que son producidas por biotecnología o ingeniería genética

La biotecnología produce nuevas variedades de plantas resistentes a ciertas plagas de insecto para evitar el uso de pesticidas

La biotecnología puede mejorar el contenido nutricional de los alimentos y su coste de producción

Existen microorganismos capaces de descomponer y depurar las aguas residuales

La producción tradicional del vino o la cerveza no se considera biotecnología

Con biotecnología se puede producir gasolina a partir de aceites

\begin{tabular}{|l|l|l|l|}
\hline VERDADERO & FALSO & NS/NC \\
\hline os & & & \\
\hline de & & & \\
\hline de & & & \\
\hline os & & & \\
\hline la & & & \\
\hline las & & & \\
\hline & & & \\
\hline or & & & \\
\hline
\end{tabular}




\begin{tabular}{|c|c|c|c|}
\hline 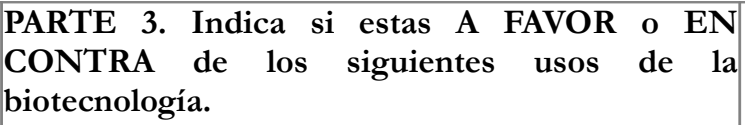 & A FAVOR & $\begin{array}{c}\text { EN } \\
\text { CONTRA }\end{array}$ & OBSERVACIÓN \\
\hline Uso de levaduras para la producción de vino y cerveza & & & \\
\hline $\begin{array}{l}\text { Uso de microorganismos genéticamente modificados } \\
\text { para depuración de aguas residuales de forma más } \\
\text { eficiente }\end{array}$ & & & \\
\hline $\begin{array}{l}\text { Alteración de genes de plantas para un mejor } \\
\text { crecimiento }\end{array}$ & & & \\
\hline $\begin{array}{l}\text { Añadir genes a plantas para que tengan un mayor } \\
\text { valor nutricional }\end{array}$ & & & \\
\hline $\begin{array}{l}\text { Alteración de genes en frutos para que tengan un } \\
\text { mejor sabor }\end{array}$ & & & \\
\hline $\begin{array}{l}\text { Alteración de genes en frutos para que duren más } \\
\text { tiempo en buen estado }\end{array}$ & & & \\
\hline $\begin{array}{l}\text { Alteración de genes de humanos para el tratamiento } \\
\text { de enfermedades }\end{array}$ & & & \\
\hline $\begin{array}{l}\text { Alteración de genes en embriones para evitar } \\
\text { enfermedades }\end{array}$ & & & \\
\hline $\begin{array}{l}\text { Usar vacas genéticamente modificadas para mejorar la } \\
\text { calidad de la carne y la leche }\end{array}$ & & & \\
\hline $\begin{array}{l}\text { Usar vacas genéticamente modificadas para producir } \\
\text { medicinas de uso humano }\end{array}$ & & & \\
\hline Insertar genes de plantas en animales & & & \\
\hline Clonación de seres humanos & & & \\
\hline Elección del color de ojos de los futuros hijos & & & \\
\hline
\end{tabular}

